\title{
PRICE OF ELECTRICITY VS DIFFERENT HEATING TECHNOLOGIES IN CZECH REPUBLIC
}

\begin{abstract}
This paper analyses both individual components of the price of electricity and the electricity rates as related to individual modes of heating. The price development has been monitored and assessed since July 1, 2001, i.e. the date on which the 'Price Decree of the Energy Regulation Office, No. 5/2001' entered into force concerning introduction of new rates and prices of electricity for households and businesses. Primarily, the rate, D 02d, was chosen for assessment. This rate is used by the majority of households as they use gas or solid fuels for heating. Further, the rate, D45d, for direct electric heating, and rates, D55d and D $56 d$, for heating by thermal pumps were also subject of assessment. Both the development trends and the comparison of the investigated rates of electricity make it obvious that prices of electricity will continue to be rising in the long-term perspective.
\end{abstract}

Keywords: Electricity market, price of electricity, electricity rate.

\section{Introduction}

The current economic situation implies ever increasing need to take into account savings concerning all aspects of human existence. No doubt, one of the substantial things we cannot ignore in our lives is keeping appropriate temperatures of our homes. Due to climatic conditions we live in, household heating must be provided for periods often in excess of eight months yearly.

After the revolution of 1989 , there was a new kind of boom concerning alternatives of household heating away from traditional ways of ensuring comfortable temperature conditions in our homes. The environmental protection priorities of the nineties of the past century made it essential to concentrate on wider use of environment friendlier household heating technologies, which meant using natural gas and electricity, the latter either directly or by ways of accumulation heaters.

The electric heating belongs among the most comfortable ways of home heating plan implementation from the point of view of the usage, readiness, service and maintenance, but also as regards aspects of environmental protection. It is readily accessible anywhere where there has been electric power of sufficient wattage installed. But due to steep rise in prices of electricity, usage of electric heaters represents the most expensive ways of providing comfortable home temperatures. Away from this advantageous mode of heating, as it was the case of the nineties of the last century, the electricity, because of the continuing rises in its prices, has become the most expensive option of ensuring household or home comfortable temperature. Nevertheless, it should be highlighted that costs of direct or accumulation electricity usage in contrast to using electrically powered heat pumps differ to the advantage of the latter.

The objective of this paper has been to provide a review of the components which the electric energy price consists of, as implication of electric energy market liberalisation, and then to analyse development trends of some electric power rates as related to specific heater usage.

\section{Electric energy market liberalisation}

The Energeticky regulacni urad (Energy Regulatory Office) was established on January 1, 2001 as decreed by the Act No. $458 / 2000$, Coll. Its principal role has consisted in regulating energy prices; supporting utilisation of renewable and secondary energy sources and combined heat and power generation; protecting customers and consumers' interests; protecting licence holders' vested interests; leading inquiries into conditions for competition; co-operating with the Office for the Protection of Competition (UOHS); supporting competition of energy industries; and providing supervision of energy markets.

On January 1, 2002 started the process of the electric energy market liberalisation in the Czech Republic. In practical terms, the former 'protected consumers of electricity' have transformed

\footnotetext{
* ${ }^{2}$ Milan Mikolas, ${ }^{2}$ Jana Bartonova, ${ }^{2}$ Jana Magnuskova, ${ }^{2}$ Dagmar Letavkova

${ }^{1}$ Institute of Mining Engineering and Safety, Faculty of Mining and Geology, VSB - TU Ostrava, Czech Republic

${ }^{2}$ Institute of Economics and Control Systems, Faculty of Mining and Geology, VSB - TU Ostrava, Czech Republic

E-mail: milan.mikolas@vsb.cz
} 
into 'rightful consumers' for whom electric energy prices are no longer subject of annual decrees of the Energy Regulatory Office and who have the right to choose electricity suppliers of their own. These rightful electric power consumers have only part of their final electricity prices regulated [1].

The electric energy market was liberalised in stages concerning specific categories of consumers:

- Since Jan. 1, 2002 - End-users consuming more than 40 GWh,

- Since Jan. 1, 2003 - End-users consuming more than $9 \mathrm{GWh}$;

- Since Jan. 1,2004-All end-users who have their consumption continually measured apart from households,

- Since Jan. 1, 2005 - All end-users apart from households,

- Since Jan. 1, 2006 - All end-users inclusive households [1].

\section{Electricity price structure}

The liberal market price of electricity basically consists of two components: delivery and production.

The former component is regulated as electric energy transmission and distribution providers are natural monopolies. The latter component of electricity production per se is determined by the producers themselves and is subject of negotiation between producers and their customers. This component is not regulated by the Energy Regulatory Office. The two-component structure of the electricity reflects situation of the electric power free market. [2]

Table 1 specifies items that electricity final prices comprise, inclusive electric power taxes and VAT.

To the regulated items of the price of the electric power delivered belong [3]:

a) Distribution costs: Payments of distribution services are divided into floating and fixed constituents. The floating constituent concerns electric energy delivery volumes, CZK/ MWh, and covers costs of distribution network losses that are directly proportional to the volumes of electric energy transferred, i.e. delivered. The fixed constituent (a monthly fee relative to the voltage class of the main circuit breaker) concerns fixed costs of the distribution provider who guarantees continuing deliveries of electricity in the quality defined. For example, the costs cover maintenance and renewal of electricity distribution networks, measurement costs, back readings, etc.

b) System service costs: These cover all allowable expenses of the distribution provider, $\breve{C} E P S$ a.s. The company, apart from the distribution of the high voltage electricity, also regulates production and consumption within the distribution network so that production is in direct proportion to specific consumption. Some of the services are out-sourced. These costs also embody transmission and distribution losses, as well as network maintenance and development expenses.

c) Costs of additional expenses related to support of renewable source electricity production, combined heat and power generation, and secondary resources: Costs of renewable and non-traditional electric energy generation are generally higher than those of thermal and nuclear power stations. All end-users participate in covering these additional costs (i.e. difference between the electricity price subsidised by $O Z E$, $K V E T$ and $D Z$, and the average market price) in the form of a regulated contribution. The support of renewable and nontraditional energy generation has been assisted by the Act No. 180/2005 Coll. on Support of Renewable Resources, and the Act No. 458/2000 Coll., on Entrepreneurial Activities and Public Administration in the Field of Energy Industries, and some Energy Act Amendments.

d) Market operator costs: They cover services of the company, OTE a.s. This company provides balances concerning supply and demand of electric power, differences between the planned and realised deliveries, as well as balances of long-term electricity consumption in the Czech Republic. All end-users participate in paying these costs.

The amount of the regulated payments is decreed annually by the Energy Regulatory Office that takes into account wishes of the subjects involved.

End-user electricity price structure

Table 1

\begin{tabular}{|l|l|l|}
\hline \multirow{2}{*}{ Regulated Items } & Electricity Distribution & Wattage Fee \\
\cline { 3 - 3 } & \multirow{3}{*}{ Concurrent services } & Price per volume of distributed electricity \\
\cline { 3 - 3 } & & System services \\
\cline { 3 - 3 } & & Accountant service provider fee \\
\cline { 3 - 3 } Non-regulated items & Electricenergy delivery & Fixed fee \\
\cline { 3 - 3 } Taxes & Electricity tax & Price for delivered electricity volume \\
\cline { 2 - 3 } & VAT & \\
\hline
\end{tabular}


Among the non-regulated constituents of the price of electricity are:

a) Fixed fee for the specific circuit breaker installed.

b) Price of electricity deliveries.

The non-regulated constituents of the electricity price are determined by individual providers who are oriented by market principles. The price of electric power derives from the price of the energy stock exchange.

The last constituent of the electricity price are taxes:

a) Electricity tax rates the amount of electric power consumed.

Since 2008, the electricity price also includes a new, so called ecological tax that is incumbent on the members of the European Union. The electrical power provider pays the tax, as a total for all his customers, to the Duty Office. The rate, $28.30 \mathrm{CZK} / \mathrm{MWh}$, is universal for all consumers. The provider does not collect this tax if the electric energy delivered has been from renewable sources.

b) The value added tax (VAT) rates the sum of all the price constituents mentioned. Until December 31, 1997, the VAT had been $5 \%$. On $1^{\text {st }}$ of January, 1998, it increased to $22 \%$, which then decreased to $19 \%$ on May 1,2005 . On $1^{\text {st }}$ of January, 2006, the electricity VAT increased again and since then the rate has been $20 \%$.

The individual constituent percentages, as related to household consumption of electric energy, are illustrated by Fig. 1. The ratios given are without taxes and VAT.

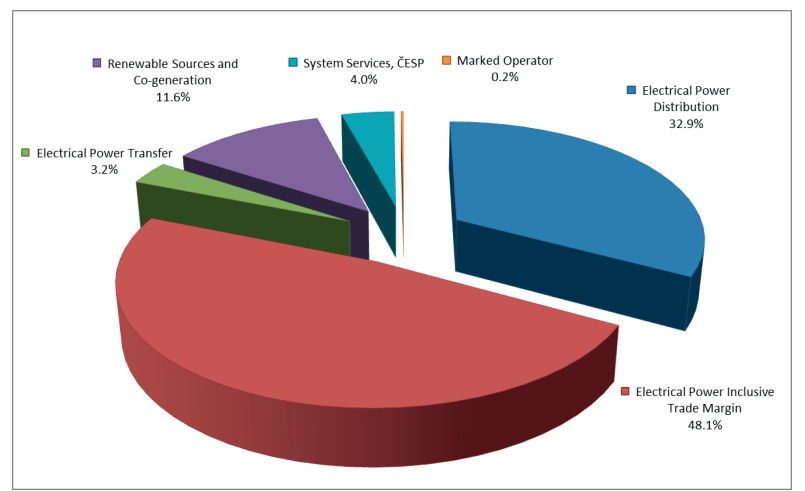

Fig. 1 Price constituent percentages as regards household electricity consumption in 2012 [4]

\section{Electric energy rates}

The electric energy rate depends on the consumption and utilisation of the electric power by household end-users. Usually, it is a fixed rate as specified by the mode of the heating utilised. The rate is designated by a symbol, D-rate number-d, for example, $D 02 d$. Currently, nine rates are valid for the households.

The households that do not use electric power for heating of the rooms and water but only utilise it for lighting and running of electric appliances (refrigerators, wash-machines, washers, microwave ovens, computers, etc.) usually have a single tariff rate, $D 02 d$, which is valid all day through for one $\mathrm{kW}$ per hour. The overall majority of household fall within this standard class.

If a household end-user uses electric power for heating, it is of advantage to negotiate a double tariff rate, NT-VT. The NT means a low tariff rate, the latter a higher one as they depend on the specific hour interval of the day. The low tariff rate interval is decided by the electricity provider in respect of the Energy Regulatory Office decrees.

Concerning the household heating, this paper has focused on these double-tariff rates:

- Low tariff rate of the operative interval, $D 45 d$, for households that use electricity for direct running of electric heaters of rooms and water. The rate is valid for minimum of 20 hours daily. [5]

- Low tariff rate of the operative intervals, $D 55 d$ and $D 56 d$, for households that run a thermal pump heating appliance which had been put into operation until 31. 3. 2005 (rate, $D$ $55 d$ ) or until 1. 4. 2005 (rate, $D 56 d$ ). The rate is valid for minimum of 22 hours daily [6].

The double-tariff options are of advantage if electric energy savings are taken into account.

\section{Development of electric energy prices}

The decisions and decrees of the Energy Regulatory Office and the price lists of some suppliers provided the input data for assessing development trends of electric energy [7]. For comparison's sake, in view of the fact that there are very many suppliers of electric power, the suppliers were chosen according to the criterion of their specific distribution area, namely E.ON Energie, a.s. (the former JCE, JME), Prazska energetika, a.s., and CEZ Prodej, s.r.o. (the former SCE, SME, STE, VCE, ZCE) because they offer distribution services for three areas. The major part of the Czech Republic is being supplied by the CEZ Distribuce, the South of the country is served by E.ON Distribuce, and Prague by PREdistribuce, see Fig. 2.

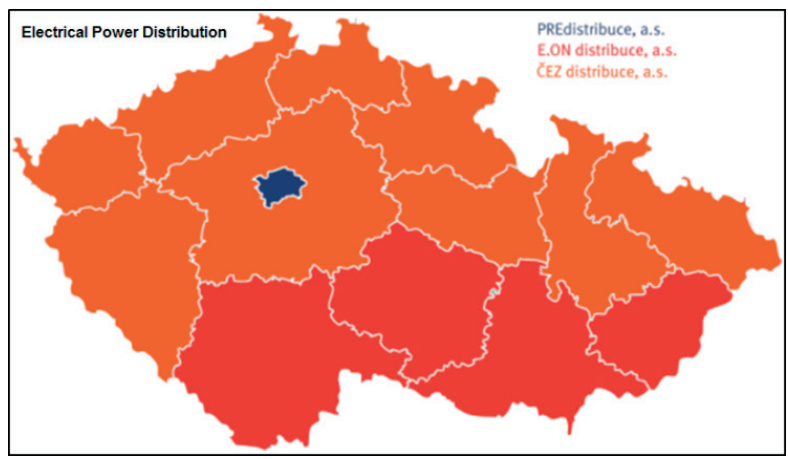

Fig. 2 Survey of distribution areas [8] 
This paper investigation started in July 2001 as on $1^{\text {st }}$ of July, 2001 new rates and prices of electric energy for households and entrepreneurs were decided by the Energy Regulatory Office (Cenove rozhodnuti ERU c. 5/2001). As noted above, the price of electricity for households depends on the heating technology utilised. That is why the rate, $D 02 d$, (used by the majority of households that use solid fuels or natural gas for heating), the rate, D45d, (specific for direct electric heater usage), and rates, $D 55 d$ and $D 56 d$, (specific for thermal pump heater usage), were taken into account so that to asses development trends of prices of electricity. A common type of the circuit breaker for households, $3 \times 25 \mathrm{~A}$, was considered when comparing development trends of fixed fees.

Figure 3 illustrates the price development of the single tariff rate, $D 02 d$ which applies to the majority of households in the Czech Republic. Until 2006 a more or less steady development can be seen. It is also obvious from this figure that prices started to rise steeply after the liberalization of the electric power market on $1^{\text {st }}$ of January, 2006, in an effort to adjust prices of electric energy in the Czech Republic to those of the European Union, which concerned all end-users inclusive households. After 2009 , this trend of steady increase was interrupted by the world economic recession. In future years, the anticipated economic revival will most probably restore the former, maybe less steeply rising trend than it had been the case for the period, 2006-2009.

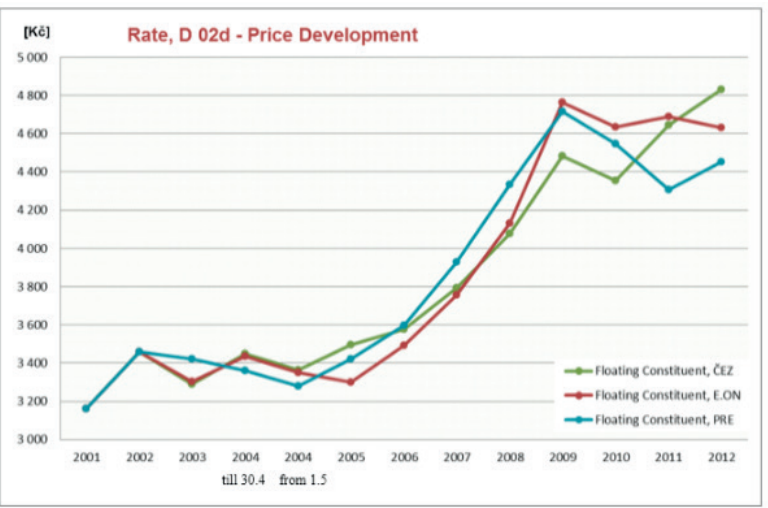

Fig. 3 Rate, D 02d - Price development, $C Z K / M W h$

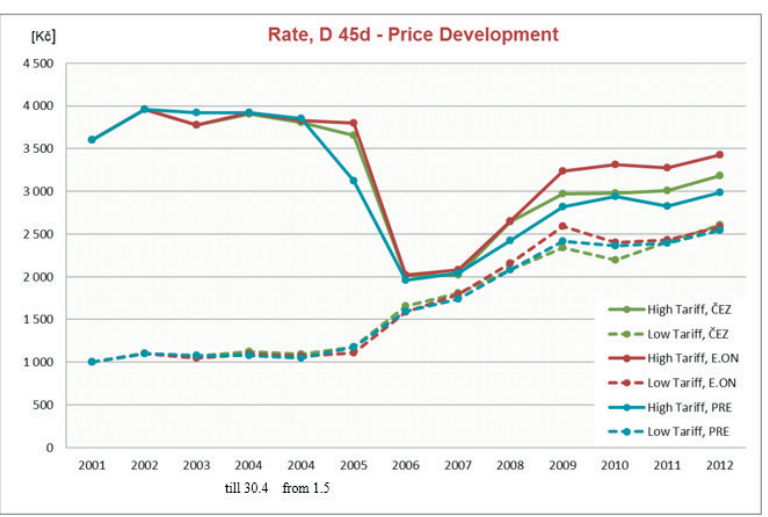

Fig. 4 Rate, D 45d-Price development
The development of the double-tariff rate, $D 45 d$, is illustrated by Fig. 4. Before the electric energy market liberalization in 2006, the low-tariff prices were increasing slightly, and the high-tariff prices slightly decreased. After 2006, ale electric energy prices started to rise steeply. The electricity producers, in greedy quest for ever increasing profit, ingeniously increased the low-tariff prices as this tariff applies to the rate, $D 45 d$ that the households use for a 20hour minimum daily. In contrast to this, the hightariff, whose operational maximum is 4 hours per day, increased in 2006 but it has started to be rising again since 2007. Both the tariff increases abated due to the world economic recession, and the low-tariff prices even slightly decreased in 2010. Currently, further rise of both tariffs has been noted.

Figure 5 informs on another double-tariff rate, $D 55 d$. This rate applies to the majority of households that utilize thermal pump for heating; the equipment which had been put in operation until March 31, 2006. In comparison to the foregoing rate, $D 45 d$, for direct electric heater usage, $D 55 d$ differs in the limits of time when low- or high-tariff rate applies. For the rate, $D 55 d$, the low-tariff minimum limit is 22 hours per day. In the past few years if costs of 1 MWH are considered, the differences between the rates D $55 d$ and D $45 d$ have been rather small in amount. The principal difference between these two rates consists in lower fixed fee as related to usage of the specific circuit breaker where the costs of $D 55 d$ application are half of those when $D 45 d$ is applied - see Table 2 .

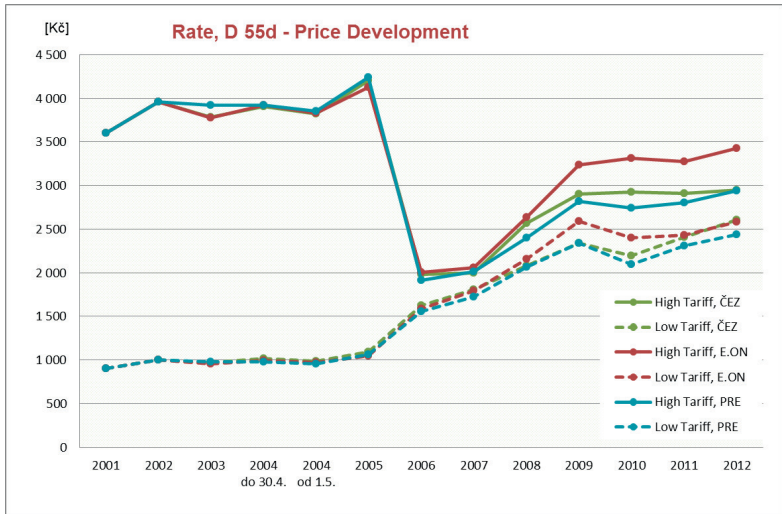

Fig. 5 Rate, D 55d-Price development, CZK/MWh

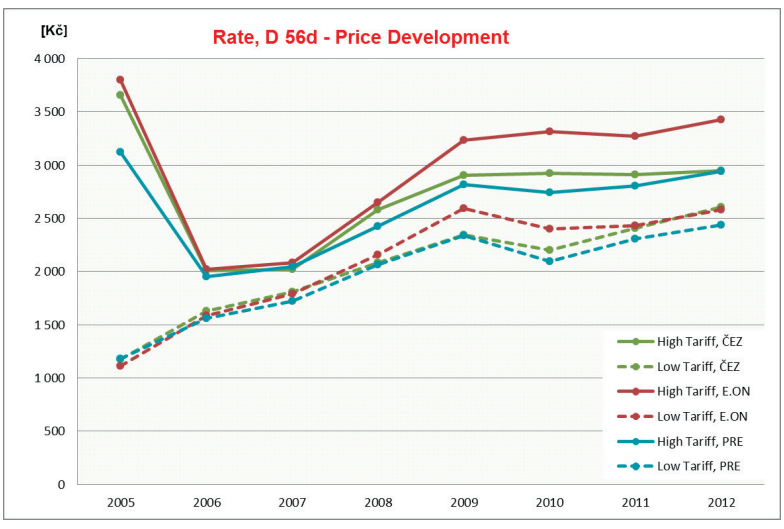

Fig 6 Rate, D 56d-Price development 
Fixed fee development for circuit breaker, 3x25 A, CEZ Comp., figures mean CZK Table 2

\begin{tabular}{|c|c|c|c|c|c|c|c|c|c|c|c|c|c|}
\hline Rate & 2001 & 2002 & 2003 & $\begin{array}{c}2004 \\
\text { until } \\
30.4\end{array}$ & $\begin{array}{c}2004 \\
\text { since } \\
1.5\end{array}$ & 2005 & 2006 & 2007 & 2008 & 2009 & 2010 & 2011 & 2012 \\
\hline D 45d & 438 & 498 & 482 & 502 & 490 & 490 & 269 & 281 & 351 & 374 & 390 & 408 & 420 \\
\hline D 55d & 178 & 215 & 211 & 217 & 211 & 232 & 95 & 113 & 119 & 148 & 157 & 167 & 179 \\
\hline
\end{tabular}

Since April 1, 2005, a double-tariff rate, D 56d, has been applied for thermal pump usage as decreed by the Energy Regulatory Office. The development of this rate is illustrated by the Fig. 6 . Step by step, the price level of the rate, $D 55 d$, for thermal pumps put into operation until March 31, 2005, is approaching the level of the rate, $D 56 d$. Currently, there is no difference between consumption at low- or high-tariff rates but the fees for specific circuit breakers only. The reason for the introduction of the two rates was in the effort to minimise impact of the electricity market liberalization on consumers who opted for usage of thermal pumps whose usage was promoted and strongly supported then. The rate, $D 56 d$, is a clear signal for the electric energy market which way the price levels of distribution rates for thermal pumps will be taking in future [8].

To make the arrangement of Fig. 7 clear, price development for rates, D $55 \mathrm{~d}$ and $56 \mathrm{~d}$, are given only for the company, $C E Z$, at which point, the $1 \mathrm{MWh}$ prices of low- and high-tariff rates have been identical since 2009. The figure also illustrates the fixed fee payments for the circuit breaker, $3 \times 25 \mathrm{~A}$ as they represent the only difference between the rates, $D 55 d$ and $D 56 d$.

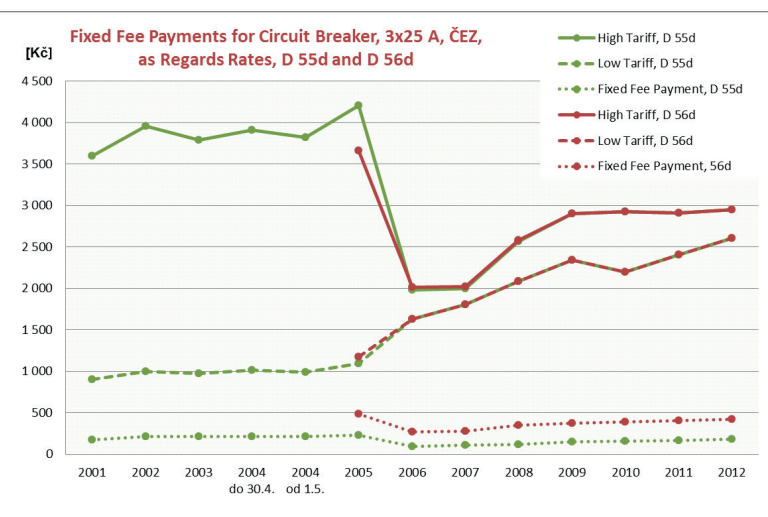

Fig. 7 Rates, D 55d and D 56d, CZK per $1 \mathrm{MWh}$ and monthly fees for circuit breaker $3 \times 25 \mathrm{~A}$ in $\mathrm{CZK}$

Figure 8 provides details of fixed fee payment as regards the circuit breaker, $3 \times 25 \mathrm{~A}$, and the rates, D55 $d$ and D56 d, concerning all supplier companies investigated. Since 2007, there has been a trend of increasing fixed fee payments. Only in 2012, the companies, E.ON and Prazska energetika slightly lowered their circuit breaker fees. The company, CEZ, has been constantly increasing the fixed fees of their circuit breakers.

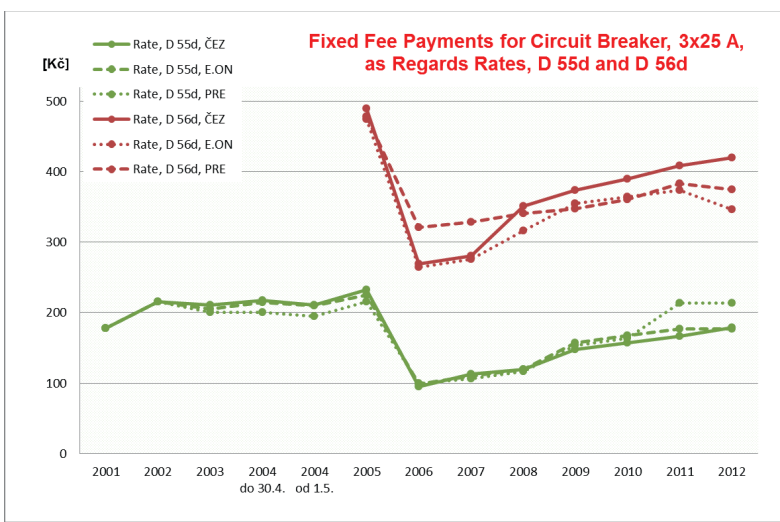

Fig. 8 Fixed fee payments for circuit breaker, $3 \times 25 \mathrm{~A}$, in $C Z K$ as regards rates, $D 55 d$ and $D 56 d$

\section{Conclusion}

It has been within the scope of this paper to provide assessment of electric energy price developments vis-à-vis usage of different household heating technologies since 2002 when new rates were introduced. The focus has been only on those rates that concern heating by solid fuels, natural gas, and electricity. For the electricity, more detailed investigations have been performed, namely concerning alternatives of using direct electric heaters or thermal pumps. The investigation results can attest to the fact that electric market liberalisation started the trend of soaring prices for all rates investigated. The Energy Regulatory Office has substantiated this steep rise in electric energy prices as implication of the rising electric energy prices on the European market, and the necessity of increasing efforts to support utilisation of renewable energy sources. In 2010, the electric power prices slightly decreased due to economic recession. The household started to economise, and the firms, because of the economic slump, needed less electric energy, which meant that the total electricity consumption went down. It might have been presumed that prices would be decreasing fast because of the market mechanism of supply and demand. Nevertheless, in our country, there is practically no competition as regards distribution of electric power and, consequently, the prices of electricity distribution rose again in 2010. What's more, also the VAT increased from $19 \%$ to $20 \%$, and the contribution to the support of alternative energy resources tripled in contrast to 2009 
[9]. Since 2011, the electricity prices have been steadily rising but the increase has been less steep than it was the case of the past period, 2006-2009. The presented Figs. 3 - 8 make the long- term development trends obvious. Stagnation or even decrease of electric power prices can hardly be anticipated.

\section{References}

[1] Eru.cz.: Electrical Energy Prices and Conditions Related (in Czech). [online]. [30-8-2012].

Available on internet: http://www.eru.cz/dias-read_article.php?articleId=172\#1, 2010.

[2] Eru.cz .: Economic and Activity Report (in Czech). [online]. [27-9-2012].

Available on internet: http://www.eru.cz/user_data/files/vyrocka06.pdf , 2006.

[3] Eru.cz .: How to Read an Electrical Energy Invoice). [online]. [20-8-2012].

Available on internet: http://www.eru.cz/dias-read_article.php?articleId=172\#4, 2012.

[4] Eru.cz.: Press Release Concerning Regulated Electrical Price Decrees (in Czech). [online]. [20-10-2012].

Available on internet: http://eru.cz/user_data/files/tiskove\%20zpravy/2011/TZelektro22\%2011\%202011.pdf, 2011.

[5] Cenyenergie.cz.: Direct Electrical Heaters (in Czech). [online]. [18-10-2012].

Available on internet: http://www.cenyenergie.cz/elektrina/clanky/d45d-primotop-a-ohrev-vody-elektrinou.aspx, 2010.

[6] Cenyenergie.cz.: Thermal Pump Rate (in Czech). [online]. [18-10-2012].

Available on internet: http://www.cenyenergie.cz/elektrina/clanky/d55d-a-d56d-sazba-pro-tepelne-cerpadlo.aspx, 2010.

[7] Tzb/info.cz.: Price Lists of Electrical Energy as Valid From 1. 1. 2012 (in Czech). [online]. [1-10-2012].

Available on internet: http://www.tzb-info.cz/prehled-cen-elektricke-energie, 2011.

[8] BLAZICEK, J.: Electrical Prices in 2011 (in Czech). [online]. [30-10-2012].

Available on internet: http://www.tzb-info.cz/ceny-paliv-a-energii/7131-ceny-elektriny-na-rok-2011, 2011.

[9] BECHNIK, B.: Support Renewable Sources and Electrical Prices (in Czech). [online]. [02-11-2012].

Available on internet: http://www.tzb-info.cz/ceny-paliv-a-energii/6184-podpora-obnovitelnych-zdroju-a-cena-elektriny, 2010. 